\title{
Validation of the method for determining the specific activity of the gel with recombinant endolysin
}

\author{
Alexey Vorobev $^{1 *}$, Mariia Anurova ${ }^{2}$, Kalimat Bagandova ${ }^{1}$, Toita Mizaeva ${ }^{1}$, Andrei \\ Aleshkin $^{1}$, Daria Vasina $^{3}$, Natalia Antonova ${ }^{3}$, and Vladimir Gushchin ${ }^{3}$ \\ ${ }^{1}$ G.N. Gabrichevsky Research Institute for Epidemiology and Microbiology, 125212 Moscow, Russia \\ ${ }^{2}$ Sechenov First State Medical University, 119435 Moscow, Russian Federation \\ ${ }^{3}$ The Gamaleya National Center of Epidemiology and Microbiology, 123098 Moscow, Russian \\ Federation
}

\begin{abstract}
A method for determining the specific bactericidal activity of the gel with the recombinant modified endolysin of the bacteriophage ECD7 has been developed. Bacterial strains to determine the specific bactericidal activity were selected and acceptance criteria were determined. The developed methodology was validated according to the indicators "Specificity", "Accuracy" and "Intermediate precision". The developed method has been successfully validated and is suitable for determining the specific bactericidal activity of a gel with a recombinant modified endolysin.
\end{abstract}

Keywords: bactericidal activity, recombinant endolysin, bacteriophage ECD7.

\section{Introduction}

Biotechnological substances and drugs are complex products, the quality indicators of which can vary from batch to batch depending on many external and internal factors (temperature, humidity, $\mathrm{pH}$, production conditions, used producer strains, etc.).In this regard, approaches and requirements for determining the quality of biotechnological products differ from those for chemicals. Thus, biotechnological products often lack a correlation between their quantitative content and biological activity (the ability of a product to cause a certain biological effect in a biological system (organism, cell culture, etc.)), and therefore, the determination of the quantitative content of a particular product does not indicate its quality [1]. As a result, the quality indicator "Assay" for a biotechnological product is replaced by the indicator "Specific activity", which indicates the biological effect characteristic of a given substance or drug [1].

Specific activity is determined according to a method developed considering the characteristics of the analyte and the biological effect that it should have. Since the method is often developed individually for each new substance, the question of the validity of this method arises, for the confirmation of which it is necessary to carry out validation.

\footnotetext{
* Corresponding author: vorobjew.alex2010@yandex.ru
} 
The aim of this work is to validate the method for determining the specific activity of a gel containing recombinant modified endolysin (an enzyme synthesized by a bacteriophage at the end of the lytic cycle and capable of destroying the cell wall of gram-negative and some gram-positive bacteria) LysECD7-SMAP [2].

\section{Materials and methods}

\subsection{Objects of the study}

The object of the study is the recombinant endolysin LysECD7 (NCBI AN: ASJ80195.1), containing at the $\mathrm{C}$-end of the molecule SMAP (N-terminal myeloid antimicrobial peptide of sheep), which enhances the permeabilizing properties of the enzyme [2,3], as well as a drug in the form of a gel containing this endolysin at a concentration of $2 \mathrm{mg} / \mathrm{g}, 5 \mathrm{mg} / \mathrm{g}$ and $10 \mathrm{mg} / \mathrm{g}$.

\subsection{Bacterial strains}

Three bacterial strains (clinical isolates) were used to determine the specific bactericidal activity: AcinetobacterbaumanniiTS 50-16, StaphylococcusaureusATCC 25923 and Escherichiacoli ATCC 25922.

\subsection{Determination of the specific activity of the LysECD7-SMAP substance and the drug}

The determination of the specific activity was carried out according to the previously published method with some modifications (bacterial strains, buffer solution) [4].

Suspensions of bacterial cells of A. baumannii, E. coli, and S. aureus strains were prepared from overnight broth cultures obtained in meat-peptone broth (MPB) in a volume of 4.5-5 ml. Overnight cultures were diluted with fresh MPB and grown at $+37 \pm 0.4^{\circ} \mathrm{C}$ in a TS-1/80 SPU thermostat (OJSC "Smolenskoe SKTB SPU", Russia) until a McFarland turbidity of 0.5 units was achieved. Turbidity was measured using a Densi-La-Meter II densitometer (ErbaLachemas.r.o., Czech Republic). The resulting cultures were centrifuged in a volume of $1 \mathrm{ml}$ at $6000 \times \mathrm{g}$ for 10 minutes, the supernatant was removed. The cells were resuspended in PBS until a McFarland turbidity of 0.5 units was reached. The bacterial cell suspension was diluted 100-fold with PBS to obtain a working suspension that was used in no more than 30 minutes to determine the sensitivity to endolysin. A working suspension of bacterial cells in a volume of $100 \mu \mathrm{l}$ was mixed with a test sample (substance or drug) in a volume of $100 \mu \mathrm{l}$ in a sterile flat-bottomed 96-well polystyrene plate (Eppendorf, Germany). The plates with the resulting mixture were incubated at $+37 \pm 0.4^{\circ} \mathrm{C}$ for 30 minutes with continuous shaking at $200 \mathrm{rpm}$ on a Shaker S-3 shaker (ELMI, Latvia). After incubation, tenfold dilutions in PBS were prepared from the samples. From dilutions 10-1 and 10-2, samples in a volume of $100 \mu \mathrm{l}$ were applied to the surface of Mueller-Hinton agar (HiMedia, India) in Petri dishes and triturated with a glass spatula until completely dry on the surface of the nutrient medium. The plates were incubated at $+37 \pm 0.4^{\circ} \mathrm{C}$ overnight, after which the colony count was performed. The assessment of the sensitivity of bacterial strains was carried out in comparison with control samples containing PBS (in the case of a substance study) or placebo (in the study of a drug) instead of the test sample. The study of experimental and control samples was carried out in three independent replicates. Specific bactericidal activity was calculated by the formula: 


$$
X=(1-A / B) * 100
$$

where $X$ - specific bactericidal activity, $\% ; A$ - the average number of bacterial cells in the experiment, $\mathrm{CFU} / \mathrm{ml} ; B$ - the average number of bacterial cells in the control, $\mathrm{CFU} / \mathrm{ml}$.

\subsection{Validation}

Validation of the method was carried out according to the indicators "Specificity", "Accuracy" and "Intermediate precision".

To validate the "Specificity" indicator, the specific activity for the substance and drug was determined by comparing the results with PBS and placebo, respectively. The acceptance criterion was the presence of a bactericidal effect in the case of the analysis of the substance and the drug and its absence in the case of the PBS and placebo analysis.

Determination of the "Accuracy" indicator was carried out by calculating the ratio " $\mathrm{X}_{\text {exp: }}$ : $\mathrm{X}_{\text {theor }}$ " according to the formula:

$$
\mathrm{Z}_{\mathrm{i}}=\left(X_{\mathrm{exp}} / X_{\text {theor }}\right) * 100
$$

where $\mathrm{Zi}$ - desired ratio, $\% ; \mathrm{X}_{\exp }$-experimental value of specific activity, $\% ; \mathrm{X}_{\text {theor- }}$ theoretical value of specific activity, $\%$. $100 \%$.

The acceptance criterion was the value of the ratio " $\mathrm{X}_{\mathrm{exp}}$ : $\mathrm{X}_{\text {theor" }}$ "in the range of 90 -

To determine the Intermediate precision, the analysis of three laboratory batches of the drug was carried out independently by two analysts in duplicate, after which the results of analyst 1 were compared with the results of analyst 2 by calculating the relative standard deviation (RSD,\%) using the formula:

$$
R S D=\frac{\sqrt{\frac{\sum\left(X_{i}-\bar{X}\right)^{2}}{n-1}}}{\bar{X}}
$$

where $\mathrm{X}_{\mathrm{i}}-$ specific bactericidal activity, $\% ; \overline{\mathrm{X}}$ - average value of specific bactericidal activity, $\% ; \mathrm{n}$ - the total number of values.

The RSD value for all results should not exceed 10\%, and for each pair of results "analyst 1: analyst 2" - 5\%.

\section{Results}

\subsection{Specificity}

When determining the specific activity of the substance and the drug, a pronounced bactericidal activity was observed, while it was not in the analysis of PBS and placebo. The determination was carried out in three independent replicates. The results are shown in Table 1 .

Thus, the method met the acceptance criteria and is specific.

\subsection{Accuracy}

To determine the Accuracy, the theoretical specific activity of the studied endolysin concentrations in relation to the bacterial strains on which the test was carried out was determined. The determination was carried out by analyzing a solution of endolysin at three concentrations: 2,5 and $10 \mathrm{mg} / \mathrm{ml}$. The theoretical specific activity was calculated as the 
arithmetic mean of the results of five independent replicates. The data obtained are presented in Table 2 .

Table 1. Determination of the specificity of the method

\begin{tabular}{|c|c|c|c|c|c|c|c|}
\hline \multirow{3}{*}{ Iteration } & \multicolumn{7}{|c|}{ Specific bactericida lactivity, \% } \\
\hline & \multicolumn{3}{|c|}{ Substance } & \multicolumn{3}{|c|}{ Drug } & \multirow{2}{*}{$\begin{array}{l}\text { PBS/ } \\
\text { Placebo }\end{array}$} \\
\hline & $2 \mathrm{mg} / \mathrm{g}$ & $5 \mathrm{mg} / \mathrm{g}$ & $10 \mathrm{mg} / \mathrm{g}$ & $2 \mathrm{mg} / \mathrm{g}$ & $5 \mathrm{mg} / \mathrm{g}$ & $10 \mathrm{mg} / \mathrm{g}$ & \\
\hline \multicolumn{8}{|c|}{ S. aureus ATCC 25923} \\
\hline $\mathrm{I}$ & 57,60 & 58,28 & 56,43 & 59,20 & 53,79 & 52,53 & 0 \\
\hline II & 56,29 & 47,37 & 57,36 & 57,31 & 49,21 & 52,12 & 0 \\
\hline III & 48,72 & 56,41 & 50,79 & 51,68 & 52,86 & 55,33 & 0 \\
\hline $\begin{array}{l}\text { Mean } \\
\text { value }\end{array}$ & 54,20 & 54,02 & 54,86 & 56,06 & 51,95 & 53,33 & $\mathbf{0}$ \\
\hline \multicolumn{8}{|c|}{ A. baumannii Ts 50-16 } \\
\hline I & 100,00 & 100,00 & 100,00 & 99,77 & 100,00 & 99,89 & 0 \\
\hline II & 100,00 & 100,00 & 100,00 & 100,00 & 100,00 & 99,89 & 0 \\
\hline III & 97,77 & 100,00 & 100,00 & 99,38 & 99,76 & 99,78 & 0 \\
\hline $\begin{array}{l}\text { Mean } \\
\text { value }\end{array}$ & 99,26 & 100,00 & 100,00 & 99,72 & 99,92 & 99,85 & $\mathbf{0}$ \\
\hline \multicolumn{8}{|c|}{ E. coli ATCC 25922} \\
\hline I & 94,89 & 100,00 & 100,00 & 95,99 & 99,70 & 99,26 & 0 \\
\hline II & 96,95 & 100,00 & 100,00 & 99,50 & 98,61 & 98,77 & 0 \\
\hline III & 94,20 & 100,00 & 99,93 & 93,53 & 98,66 & 99,43 & 0 \\
\hline $\begin{array}{l}\text { Mean } \\
\text { value }\end{array}$ & 95,35 & 100,00 & 99,98 & 96,34 & 98,99 & 99,15 & $\mathbf{0}$ \\
\hline
\end{tabular}

Table 2. Theoretical values of the specific activity of endolysin, $\%$

\begin{tabular}{|c|c|c|c|}
\hline \multirow{2}{*}{ Strain } & \multicolumn{3}{|c|}{ Endolysin concentration, $\mathbf{m g} / \mathbf{m l}$} \\
\cline { 2 - 4 } & $\mathbf{2}$ & $\mathbf{5}$ & $\mathbf{1 0}$ \\
\hline A. baumannii TS 50-16 & $97,39 \%$ & $99,73 \%$ & $100,00 \%$ \\
\hline E. coli ATCC 25922 & $96,72 \%$ & $100,00 \%$ & $99,92 \%$ \\
\hline S. aureus ATCC 25923 & $53,89 \%$ & $53,20 \%$ & $56,11 \%$ \\
\hline
\end{tabular}

Then the analysis of three laboratory series of thedrug was carried out in three independent replicates and the ratio " $X_{\exp }: X_{\text {theor }}$ ". Table 3 shows the values of " $X_{\exp }$ : $\mathrm{X}_{\text {theor", }}$, all values meet the specified criteria.

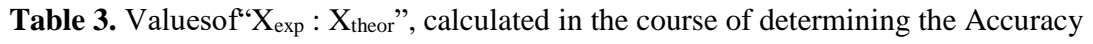

\begin{tabular}{|c|c|}
\hline Strain & "Xexp $: \mathbf{X}_{\text {theor", } \%}$ \\
\hline A. baumannii TS 50-16 & 100,81 \\
\hline E. coli ATCC 25922 & 99,28 \\
\hline S. aureus ATCC 25923 & 98,91 \\
\hline
\end{tabular}

\subsection{Intermediate precision}

When determining the Intermediate precision, the analysis of three laboratory batches of the drug was carried out in two independent replicates by two analysts on different days using the same equipment.

The calculated RSD values are presented in Table 4. 
The determined indicators met the acceptance criteria, and the method was successfully validated for this indicator.

Table 4. Determination of Intermediate precision

\begin{tabular}{|c|c|c|c|}
\hline \multicolumn{2}{|c|}{$\mathbf{X}_{\mathbf{i}}$} & \multirow{2}{*}{ Stand. dev. } & \multirow{2}{*}{ RSD } \\
\hline Analyst 1 & Analyst2 & & \\
\hline \multicolumn{4}{|c|}{ S. aureus ATCC 25923} \\
\hline $59,20 \%$ & $56,35 \%$ & $2,02 \%$ & $3,49 \%$ \\
\hline $51,68 \%$ & $48,76 \%$ & $2,06 \%$ & $4,11 \%$ \\
\hline $53,79 \%$ & $52,00 \%$ & $1,27 \%$ & $2,39 \%$ \\
\hline $52,86 \%$ & $53,39 \%$ & $0,37 \%$ & $0,71 \%$ \\
\hline $52,53 \%$ & $56,11 \%$ & $2,53 \%$ & $4,66 \%$ \\
\hline $52,12 \%$ & $55,87 \%$ & $2,65 \%$ & $4,91 \%$ \\
\hline \multicolumn{4}{|c|}{$\begin{array}{l}\text { Values for all results } \\
\end{array}$} \\
\hline \multicolumn{2}{|c|}{ Stand. dev. } & \multicolumn{2}{|c|}{$2,76 \%$} \\
\hline \multicolumn{2}{|c|}{ RSD } & \multicolumn{2}{|c|}{$5,14 \%$} \\
\hline \multicolumn{4}{|c|}{ A. baumannii TS 50-16 } \\
\hline $99,77 \%$ & $100,00 \%$ & $0,16 \%$ & $0,16 \%$ \\
\hline $100,00 \%$ & $100,00 \%$ & $0,00 \%$ & $0,00 \%$ \\
\hline $100,00 \%$ & $100,00 \%$ & $0,00 \%$ & $0,00 \%$ \\
\hline $100,00 \%$ & $99,84 \%$ & $0,11 \%$ & $0,11 \%$ \\
\hline $99,89 \%$ & $100,00 \%$ & $0,08 \%$ & $0,08 \%$ \\
\hline $99,78 \%$ & $100,00 \%$ & $0,16 \%$ & $0,16 \%$ \\
\hline \multicolumn{4}{|c|}{$\begin{array}{l}\text { Values for all results } \\
\end{array}$} \\
\hline \multicolumn{2}{|c|}{ Stand. dev. } & \multicolumn{2}{|c|}{$0,09 \%$} \\
\hline \multicolumn{2}{|c|}{ RSD } & \multicolumn{2}{|c|}{$0,09 \%$} \\
\hline \multicolumn{4}{|c|}{ E. coli ATCC 25922} \\
\hline $95,99 \%$ & $98,30 \%$ & $1,63 \%$ & $1,68 \%$ \\
\hline $99,50 \%$ & $98,08 \%$ & $1,00 \%$ & $1,02 \%$ \\
\hline $99,70 \%$ & $99,65 \%$ & $0,04 \%$ & $0,04 \%$ \\
\hline $98,61 \%$ & $99,30 \%$ & $0,49 \%$ & $0,49 \%$ \\
\hline $99,26 \%$ & $94,28 \%$ & $3,52 \%$ & $3,64 \%$ \\
\hline $98,77 \%$ & $98,97 \%$ & $0,14 \%$ & $0,14 \%$ \\
\hline \multicolumn{4}{|c|}{ Values for all results } \\
\hline \multirow{2}{*}{\multicolumn{2}{|c|}{$\frac{\text { Stand. dev. }}{\text { RSD }}$}} & \multicolumn{2}{|c|}{$1,63 \%$} \\
\hline & & \multicolumn{2}{|c|}{$1,66 \%$} \\
\hline
\end{tabular}

\section{Conclusion}

Thus, in the course of this work, the method for determining the specific activity of the LysECD7-SMAP recombinant endolysin substance and the gel containing it was successfully validated.

All determined indicators met the acceptance criteria, which indicates the suitability of the method for determining the Specific activity.

\section{References}

1. J.C. Robinson, C. Jones, Bioanalysis, 3(1), (2011) doi: 10.4155/BIO.10.161

2. Antonova NP, Vasina DV, Rubalsky EO, et al. Biomolecules, 10(3) (2020) doi: $10.3390 /$ biom 10030440

3. Antonova N.P., Vasina D.V., Lendel A.M., Usachev E.V., Makarov V.V., Gintsburg A.L., Tkachuk A.P., Gushchin V.A. Viruses, 11, 3(2019) doi: 10.3390/v11030284 